Philosophy and Progress: Vols. XLIX-L, January-June, July-December, 2011 ISSN 1607-2278 (Print), DOI : http://dx.doi.org/10.3329/pp.v50i1-2.11923

\section{INDUBITABLE TRUTH IN SCIENCE?}

\section{Siddhartha Shankar Joarder*}

\section{Introduction}

The very nature of the growth of scientific knowledge, whatever the field or scope may be, is always a subject of corrigible or amendable truth and this standpoint has been supported by the historians of science. So there are many causes to be sceptical about science and its development on the way to its maturity. Sceptical scheme of the philosophy of science makes the right way to unravel the mystery of nature. Therefore, every sort of knowledge in human progress has been thought to be an incomplete scheme because we actually do know very little about the complete truth or may be this can never be known at all! Probably there is no single knowledge in the world which cannot be doubted somehow. Bertrand Russell (1872-1970) has rightly raised the question, 'Is there any knowledge in the world which is so certain that no reasonable man can doubt it?' 1 He has given the inklings of the nature of philosophy as well as all possible human thoughts where there is no scope of being complacent with unquestioned knowledge.

\footnotetext{
* Assistant Professor, Department of Philosophy, Jagannath University

E-mail : siddharthakjhe@gmail.com
}

Sceptical scheme of human cognition determines the progression of our epistemic advancement. So scepticism becomes very efficacious tool in furnishing social and scientific endeavour. If this had been absent in scientific discourses in the history there would have been no result or may have a little progress in past scientific amelioration. Science becomes an inevitable part of our philosophical thoughts; therefore, philosophy of science becomes an essential compatriot of scientific advancement. In recent scientific inventions philosophical inquisitiveness paved the way to the scientists to uncover the secrecies of the nature with utmost precision. Albert Einstein (1879-1955), the greatest philosopher of science in history, has underscored the need of epistemological scheme of human thought in science. He emphatically says, without philosophy science may turn to be primitive or chaotic. Accordingly, philosophy of science raises important questions about the result of science and its validity all together which is usually taken to be granted. This paper tries to examine the history of science and its major turning points hopping to get support of the reality that science is no rigorous or antiquated branch of human thought, unlike theological belief, where there is an immense scope of making every correction or create new knowledge. Before going in detail, this should be clarified that every scientific turning point, i.e., shifting one paradigm from another, is thought to be an act of philosophical routine work where there is a huge speculations over the issues which is being done by the philosophers of science. Therefore, the Theory of Relativity or Quantum Mechanics in modern physics have been thought to be the highest form of our philosophical speculation in the field of science. This is not untrue that modern science, whatever the field is, has reached its highest 
point which has the close affinity with speculative philosophy. Philosophy is not a distinct chapter of thought for the scientists now. Albert Einstein or Niels Bohr or Heisenberg or Stephen Hawking of present day, for example, are equally envisaged as philosophers as well as scientists of course.

\section{Major philosophical debates over some critical scientific issues}

The long history of science reflects the controversies and contradictions over the issues of their methodological approach as well as their content. The contradiction or the debate comes due to the function of philosophical inquiry in the progress of science. The theory of science is a mathematical model of human observation. It is evident that sometimes this model becomes very ineffective or insufficient when it appears to be incongruent with the prediction. So to make a solution between the theories which does contradict each other needs philosophical function. The age of this contradiction is very old. It is actually a movement within science which formally starts from Francis Bacon's (1561-1626) theory although its root perhaps goes as back far as to Socrates. Dialectical process of Socrates in philosophy was the oldest methodology that creates inspiration to the philosophers of sciences to solve their dispute between rival theories. Bacon was the first man in history who introduced the inductive method in philosophy. As there is always a case of probability in the result of this method, so there was created a great deal of uncertainty and thereby scepticism. Bacon's meta-theoretical questions about the nature of our experimental procedure laid the foundation of scientific philosophy. So in the history of philosophy of science he is thought to be the prophet of modern science. Moreovers
Copernicus (1473-1543), Kepler (1571-1630), Galileo (15581642), Newton (1643-1727), Einstein (1879-1955), Niels Bohr (1885-1962) Max Planck (1858-1947), Erwin Schroedinger (1887-1961), Heisenberg (1901-1976), Max Born (1872-1970), L. De Broglie, Stephen Weinberg(1933-) among many other philosophers of science are the pioneers of the total journey. Philosophy of science is a critical exposition of science which justifies the origin, co-relation, reliability and validity of scientific knowledge. It is rather an inevitable part of science sometimes named as inductive metaphysics. Pravas Jivan Chaudhury says, "Philosophy of science in one of its capacities and functions may be identified with inductive metaphysics ... In the first respect it is different from deductive metaphysics, and in the second from such philosophy as generalises from commonsense knowledge." 2 He further says, "its objects (entities or laws) are metaphysical or transcendent in the sense that they apply directly to scientific objects only and very remotely to brute reality or data of experience; the scientific objects (entities or laws) apply less remotely (sometimes directly too) to brute reality."3 A.C. Benjamin holds, "If the task of science is to explain scientific data by means of scientific hypotheses then the task of philosophy of science is to explain philosophical data by means of philosophical hypothesis"4 It cannot be denied that each philosophical debate makes room for higher functioning of science. It is thus convenient to the scientists to think more seriously with its utmost perfection. The history of science is very old but its recent advancement has surpassed all historical records. It has thus reached at its highest point at every level of thought. Scientific philosophy examines and justifies the knowledge of science which is apparently thought to be true. It also tries to 
authenticate the rival theories of the same issue. "This is a critical enquiry into science as to its epistemological basis and ontological status. Thus the question of origin, scope and validity of science and of inductive metaphysics raised on it, must be dealt with and the order of reality to which they belong must be settled by philosophy of science." 5 We are now ready to have a look at the history of science to follow this reality. At the out set, we will start to focus on such an important issue that the human outlook has had a revolutionary change over the stratification of solar system.

\section{Geo-centric vs Helio centric debate}

The most interesting as well as important philosophical issue is possibly about the creation of the universe where we do live in for innumerable period. This question became so much perplexing and abstruse that many philosophers of science do involve in serious debate over this issue incredibly. And this might be the oldest question in history where philosophers were divided into two groups. Many of them were in favour of Geocentric theory while very few did believe that not the earth but the sun is the centre of the system which is thought to be the heliocentric theory. It cannot be denied that every subsequent philosophical work was affected by this fundamental issue very significantly. People were influenced tremendously by the theosophical belief concerning the birth and evolvement of this universe before the 15th century. In the history of human thoughts people use to believe in Aristotelian idea of cosmos before scientific model was first introduced by Copernicus and Galileo. Aristotle's hypothesis was grounded upon some false idea which was actually devoid of reality. His imagination was enshrouded by some mystic calculations. Bertrand Russell criticized Aristotle in his classic History of Western Philosophy. Russell says,

"The view that the heavenly bodies are eternal and incorruptible has had to be abandoned. The sun and the stars have long lives, but do not live for ever. They are born from a nebula, and in the end they either explode or die of cold. Nothing in the visible world is exempt from change and decay; the Aristotelian belief to the contrary, though accepted by medieval Christians, is a product of the pagan worship of sun and moon and planets." 6

Galib Ashan Khan says that Aristotelian belief in cosmology was science-like thought but not purely science. ${ }^{7}$ Actually, Aristotle's Physics was far away with science which ends with the unmoved mover. His physics was incompatible with the Newton's theory of motion. Despite the fact that Aristotle makes many spurious comments over cosmology he is the first man in Greece to try to make sunder cosmic idea from the imaginative fancy. Therefore, he is thought to be the pioneer of cosmic thinking in all time of history. Ptolemy (c.85-c.165), another Egyptian priest, also describes the earth as the motionless celestial bodies. In his important work Alamagea Ptolemy explicates a motionless earth that is spherical in size and positioned at the centre of the universe. I think Ptolemy's model was also science-like thought, not purely science, although his view was far better than Aristotle. He adds epicycle after epicycle to the original shape of the earth which he finds from his ancestor. His new earth was the centre of the system where everything was revolving round it. He added epicycle after epicycle to the shape of the earth to maintain his possible calculation. Except Aristarchus (c.310BC-230BC), the first Greek in history, nobody could realize the truth about the 
stratification of the solar system who first proposed the heliocentric theory of the universe. But nobody paid heed on the 'new' and 'sudden' idea of a stranger. Because the inveterate idea about the system was so much stout and established that it was rather difficult to uproot that. People did respect them (Aristotle, Ptolemy) exceedingly so people didn't dare to put forward any alternative proposal before them at their time.

Copernicus (1473-1543) has written an outstanding book on astrophysics which was published at the same year of his death. In his book De revolutionibus orbium coelestium (On the Revolutionibus Orbium Celestial Spheres) he has expounded the first scientific outlook of the universe that is called heliocentric model. It is evident that this idea was first proposed by Aristarchus. It does contradict with the Bible and hence faces stiff challenges from the evangelists. Copernicus has proposed that every thing in the world revolves round the sun so the earth was replaced by sun but it faces furious confrontation from almost every people of their time. As the Bible does not allow any experimental view against it so they didn't allow him to place any comment surpassing their beloved scripture.

The question then arises, who is correct --Ptolemy or Copernicus? How do we come to know the reality? Which one is science? Which one really expresses the fact exactly from the observer's point of view? Were Aristotle and Ptolemy's idea insufficient or inappropriate? What then science is?

I think, science means exploring the fact by 'true' observations keeping aside the emotion and personal inclination from the calculations. Here 'true' means the proper relationship between observer and the object that are being observed. Science is always thought to be justified knowledge. Aristotle and Ptolemy --both of them are non-factual in their hypothesis and full of miscomputations. Copernicus was a scientist and his observation was very close to the reality. His hypothesis was built on acute sense of reality. But in spite of the fact that Copernicus' view did work well and satisfied the formula, it would be unwise to think it to be final. Kepler, who studied the motion of Mars, indicated that the path of the planets is not fully round but elliptical. Here if we elucidate the view of Copernicus in science we must remember that science always do corroborate with the fact but that does never guarantee us that the picture is found might be devoid of any confusion. The history of science does disproof the thought of absolutism. As we can see that the model of Copernicus was also modified by his colleagues later on. Thomas Samuel Kuhn (1922-1996), has elaborated the notion of paradigm, which is a conceptual framework on which scientific theories are constructed. In his book The Structure of Scientific Revolutions, he has proposed that shifting one paradigm from another is a usual work of normal science. So, shifting from the notion of Ptolemy to Copernicus is rather a routine function of philosophical deed. Now let us have some other look on crucial debate in philosophy of science.

\section{Determinism vs Indeterminism}

Whether this big universe is determined or not that is rather a big question for the philosophers. This question has also been immensely thought in physics. Among many other questions determinism in physics is very important. We have an idea of different kinds of determinism in science and philosophy. In physics determinism in classical science became the central 
point of calculations. In bioengineering science genetic map is going to be read soon of human body by the biologists where there will be a revolution in human exploration. It is expected that if this is done successfully, every disorder or malfunction of human body would have been read earlier and thus be cured by reading the code. Scientists are really happy with their prediction when it works well during the time of operation. In dynamics for example, determinism is a respected tool of thoughts to the physicists.

We can calculate the velocity of a projectile maintaining its law. Every projectile follows the rule of nature, if the same condition prevails in the future it does never act otherwise. According to the law of dynamics, it is possible to determine the velocity of a projection very accurately. Successful operation of satellite and accurate projection of rocket engineering are the best example of deterministic factor in physics. Suppose, a ball is thrown from a $128 \mathrm{ft}$ mountain with the velocity of $64 \mathrm{ft} / \mathrm{sec}$ having $30^{\circ}$ elevation. We can compute its time and velocity and the distance where it will be on the ground.

Here, $\mathrm{OP}=128$

$128=-\left(64 \operatorname{Sin} 30^{\circ}\right) t+1 / 2 \mathrm{gt}^{2}$ [ Here the sign of subtraction is taken because at the point $\mathrm{P}$, velocity is active towards upwards]

$$
\begin{aligned}
& \text { or, } 128=-32 \mathrm{t}+16 \mathrm{t}^{2} \\
& \text { or, } \mathrm{t}-2 \mathrm{t}-8=0 ; \quad \mathrm{t}=4 \\
& \begin{aligned}
\text { Now, OA } & =\text { the distance fall after } 4 \text { sec. } \\
& =64 \cos 30^{\circ} \times 4 \\
& =256 \\
& =128
\end{aligned}
\end{aligned}
$$

Velocity at the point $\mathrm{A}=\mathrm{v} \cos 30^{\circ}$ (For detail, see the law of dynamics in Physics)

$$
\begin{aligned}
& =64 \cos 30^{\circ} \\
& =32
\end{aligned}
$$

So, the projectile will fall at the distance of $128 \mathrm{ft}$ with the velocity of 32 after $4 \mathrm{sec}$. This determinism is quiet acceptable to every mathematician as well as ordinary people. By using this principle scientists have invented their theories which never act against the nature. Therefore, every theory about nature becomes very reliable to them. They never questioned anything against any theory about the world. In philosophy the theory of causation or causal theory is extremely venerated. But in modern science the classical views ceases to be in operation. It does not work out in the very minuscule portion of the particle. The causal theory in physics became at stake with the advent of new physics. Einstein's Theory of Relativity changes the notion of the theory of Newton. So, the causal theory or determined world became very unstable and relative in terms of the observer's position and the time he keeps in. In the Special Theory of Relativity Einstein says, the speed of light does not depend on the source of the observers, motion; it is always constant(c). This is a strange idea which is really difficult to believe. Suppose, you are driving a car at the speed of $100 \mathrm{~km} / \mathrm{hr}$ and your friend is also coming across you at the same speed. You may think that the speed of your friend's car is $200(100+100) \mathrm{km} / \mathrm{hr}$. This is of classical idea of motion. But Einstein finds that for the case of light the speed might always be the same. It is thus revolutionary idea which is supposed to be impossible to the ordinary mind. Hawking says in his A Brief History of Time -"Newton's laws of motion put an end to the idea of absolute position in space. The theory of relativity gets rid of absolute time. Consider a pair of twins. 
Suppose that one twins goes to live on the top of a mountain while the other stays at sea level. The first twin would age faster than the second. Thus, if they met again, one would be older than the other. In the case, the difference in ages would be very small, but it would be much larger if one of the twins went for a long trip in a spaceship at nearly the speed of light. When he returned, he would be much younger than the one who stayed on Earth. This is known as the twin paradox"8 It really smashes our old idea about space and time. According to bare eyes it is near improbable to happen. In the General Theory of Relativity space and time are dynamic: "when a body moves, or a force acts, it affects the curvature of space and tine --and in turn the structure of space-time affects the way in which bodies move and forces act". 9

These questions make us seriously puzzled where there is a little scope to come out of the situation. In classical science it is believed that there is an external world whose existence could never be questioned. In philosophy this idea is called realism. Objects are always existent independently of the observer. Whether anybody observe an object or not, it is always existent in all circumstances. Newton, although a metaphysician in nature, was a realist in philosophical sense.

When I usually go outside of my room I should never think my table ceases to be existent at that moment. But the question makes a trouble when we ask, if a straight stick is taken into the water and if it is looked crooked what does it really imply? Is it crooked or straight----what should be taken as real? In the classical tune observer and the circumstances were ignored outrightly but in the later period serious philosophical debate came up from the anti- realists. They usually hold that every object in the world depend on the observers for its observance. Therefore, circumstances and environment of the observer are taken into consideration. If any cloths are looked green in the sodium light it should never be correct to think it exactly the same colour as it is found. The position, light, environment or even mentality of the observer affects the perception of an observer impossibly. So, there had been an important issue whether there is any objectivity of an object.

With the advent of new physics i.e., quantum mechanics, this new idea became a challenge for classical physics. There had been an uncertainty in the small area of the atom. The mysterious behaviour of an electron makes the things very difficult to an observer. Its oscillating character is so much capricious that nobody could be able to determine its mass and velocity at a time. If the mass is determined, velocity becomes indeterminate or vice versa. In the twenties of the last century Heisenberg, a noted physicist, made the invention and but failed to determine the exact properties of an electron. "The uncertainty principle had profound implications for the way in which we view the world. Even after more than fifty years they have not been fully appreciated by many philosophers, singled an end to Laplace's dream of a theory of science, a model of the universe that would be completely deterministic." 10 This can be analogous with a story. One day the prime minister of a country desired to see the secretariat, with her own eyes, how is it functioning? Prime minister declared her decision before a week meanwhile; all the irregularities were done away with from the office by the administration within this time. Prime minister could not be able to see the exact picture. The advisors said her to go there in disguise. But this time she was not 
allowed to enter the secretariat by the gatemen as she was thought to be an ordinary visitor. Finally, this becomes impossible for the prime minister to see the administration. This is very similar to that of an observer who is actually trying to determine the character of an electron. "For the Heisenberg principle, besides setting a limit to the uncertainty involved in a measurement, is itself limited in scope of operation; the movement in the macro-world (where the size of objects is average) involve bodies which are completely large while the Indeterminacy is comparable to the wave length of light." 11 Einstein, the founder of the quantum mechanics, didn't concede the very character of the particle. Since Newton, the theory of causation or causal theory was the main operational object in science and in our ordinary life. Every fact in the world is being explained by causal theory superbly. So there is a strong determinism in science which is called scientific determinism. But the classical notion breaks down with the advent of new science i.e., quantum physics. Einstein believed in a very certain and determined universe. He also thought that this universe is a splendid explication of cosmic beauty. Nothing happens here fortuitously. Over this issue, he has had a furious debate with Niels Bohr who didn't agree with Einstein in every respect. He was greatly influenced by the principle of uncertainty. Many physicists of course, thought it to be the inabilities of human mind to determine the position of its character accurately. Einstein says, 'The indeterminism which belongs to quantum physics is subjective indeterminism. It must be related to something, else indeterminism has no meaning, and here it is related to our own inability to follow the course of individual atoms and forecast their activities' 12 .
Einstein even believed that, scientists may develop the power of perception in future by which they can find the causality in the very depth of the particle. It was the last dream of Einstein that a grand unification theory will be invented soon by which scientists could explain the universe with utmost precision. This dream is also nourished by Stephen W. Hawking, noted physicist of present world, expresses many times in his book about the Theory of Everything. In his famous book The Grand Design he hoped that 'the universe is comprehensible because it is governed by scientific laws; that to say, its behaviour can be modelled.' 13 The principle of uncertainty has smashed the dream of the scientists who actually believe in a very gentle universe. It is calculated that we will never be able to measure it however the precision is. It is not the case of our inabilities or may not be the technical disadvantages but the reality is that it is non measurable indeed.

Hawking started his writings by mentioning the famous quotation from Einstein 'The most incomprehensible thing about the universe is that it is comprehensible'. It is implied that this universe has been running according to the law of the nature. So, when we will be able to explore the secrecy of the nature correctly we must discover the inner beauty of the universe. There are four different fields in the nature (Gravity, electromagnetism, weak nuclear force, strong nuclear force). ${ }^{14}$ They are believed to be the different form of the same phenomena. It is an explication of the same nature. When these four fields are to be taken in the same boat then we will be able to invent a Grand Unification Theory (GUT) by which the big cosmos can be understood. And he hopes that finally this may be invented soon. 
The big question came up before us --is this universe determined? Or is it possible to compute the mind of the nature? Or can't it be measured ever? What does it mean when we say that scientific laws are the explanation of the phenomena? Can we be able to understand an abstruse mind of the nature? Why there is something rather than nothing? Finally, what is reality?

This ever perplexing issue make the subject very crucial for the scientists. So they invoke philosophers to make a solution over these fundamental questions. The history of science makes us sceptical over this issue. We may thus question, which one is correct? What is truth indeed?

The debate over certainty claim in science makes the scepticism became an important weapon to challenging the knowledge in science. A.C Grayling says in one of his articles, "In both the ordinary and the philosophical senses, a sceptic is one who, at least unless he is shown satisfactory reason why he should do otherwise, doubts some proposition, belief, or theory. Sceptical consideration are immensely important for philosophical inquiry into questions about knowledge". ${ }^{15}$ Grayling scored the need of scepticism vehemently for epistemological advancement. It helps us to make understand how scientific knowledge is possible. It is actually a challenge within science which shows us how we know.

\section{Steady-state theory vs big bang theory}

Many people in the world do believe that this universe is everlasting which has no beginning or end. As it is an act of God so it never started at any moment of the history. It is static and steady. It is always as extent as ever. It has no change or no decay. This theory holds that, matter is continuously created out of empty space. Three prominent astronomers- Fred Hoyle (1915-2001), Thomas Gold (1920-2004), Herman Bondi (19192005) are the prominent exponents of the theory. This idea was dominant among the scientists of seventieth, eighteenth and nineteenth century. The prediction of the General Theory of Relativity was that--the universe is expanding. But Einstein himself didn't believe in expending universe in 1915. He strongly believed in the static universe and it is so strong that he added an element in Newtonian theory and Gravitational force to keep it infinite. ${ }^{16}$ It was very good to think a finite universe for the God-believing people because God is perpetual and His act is perfect and hence it is everlasting.

Since the last century more especially from 1920s people have rejected the idea of static universe. This was first proposed by American astronomer Edwin Hubble who has invented modern telescope in 1929. He noticed that the galaxies were deporting from each other and there is a red light shift during the time of expansion. He followed : red shift of light does imply that once upon a time they were at a same place and particularly in the same point having immensely dense with tremendous pressure along with extreme heat. This is called 'hot super dense state'. In physics the moment is thought to be 'singularity point'. Hubble calculated the age of the universe by using Doppler Effect ${ }^{17}$ Hubble's famous equation is: Speed $=$ Hubble Constant x Distance.

The rate of the expansion of the galaxies indicates that possibly 1.4 billion years ago they were at the same point. George Lemaitre, a Belgian astronomer, supported the hypothesis which got a strong basis of the theory. Lemaitre's idea was placed before the British Association for the 
Advancement of Science in 1931. His model was publicly proclaimed which started a new history in astrophysics. When we sketch two dots on the skin of balloon, the radius and the distance of the dots will be increased. This simple equation make him understand that the galaxies are deporting from each other and once upon a time possibly near one and half thousand core years ago this universe came into being through a big explosion that is known be Big Bang theory. This theory was supported by the fact of cosmic back ground radiation in 1964 . George Gammow (1904-1968) a Russian physicist has introduced this notion as an established theory in astrophysics.

Many universes might have been created like ours during the time of explosion. We actually are lucky that we have found a universe which just follows the rules of phenomena and tends not to break the law. Accordingly, scientists are in great complacence inventing the law of nature because nature never acts capriciously. Some people do believe that this big universe is an explication of great beauty. The philosopher of science deals with the function which is quietly different from the ordinary people. Christopher Caudwell says 'even the man in the street is aware that all is not well with physics; and in many cases the cracks which are rapidly developing in the structure have been stopped up by mystical notions new to science.' 18

Are all these above theories devoid of confusion? The history of science does not speak so. We have never found any theory that is proved to be absolutely final. From that point of view Feyerabend (1924-1994) an American epistemological anarchist went against for every kind of method in science. He conceives that the history of science is full of confusion and accidents. His comments on science are as follows:
$[\mathrm{S}]$ cience is a complex and heterogeneous historical process which contains vague and incoherent anticipations of future ideologies side by side with highly sophisticated theoretical systems and ancient and petrified forms of thought .... Many of the conflicts and contradictions which occur in science are due to this heterogeneity of the material, to this 'unevenness' of the historical development. ${ }^{19}$ Khan does not accept the position of Feyerabend as he has rejected the idea as saying 'it is an utterly unacceptable position' 20

\section{Newton vs Einstein's universe}

Newton's law of motion ${ }^{21}$ is a superb explanation of the nature where it only works within the limited sphere of the world. It can only be applied to the thing which is much slower than the motion of light. This was never known to the people before Einstein that it does not work for the body which has got the speed near to the light. Newton's three important theories of motion achieved tremendous success in the field of limited scope. It can predict the motion of an object very accurately. In his Principia Newton first proclaimed that every particle of the universe attracts another and its rates depend on their distance. According to this law, every thing in the world-- sun, moon, star, planets for example, were accurately measured to their movement. In addition to that, all the motion of celestial bodies were nicely calculated by this law. Nothing was wrong to that law. In Newtonian paradigm time and space was thought to be absolute. His absolute space are infinite homogeneous, continuous entities, entirely independent of any sensible object or motion by which we try to measure them'22. Space and time are meant by Newton was the continued occupancy by God. He writes, 'By existing always and everywhere God constitutes 
duration and space ... In Him are all things contained and moved.'23 Newton describes God as all-pervading and allknowing being. His concepts of 'absolute space was reinforced by the concept of ether, which was regarded as pervading all spaces, and with respect to which all things were alleged to have absolute motions.' 24

The General Theory of Relativity of Einstein helps us to assume that it is not sufficient to think the gravitational force as it only attracts two bodies as Newton thoughts, but there must be added 'apparent force' which is produced by the curvature of space-time. It is one of an important hypothesis of the General Theory of Relativity that every particle; however small it is, affected by the curvature of the space-time. Even it affects the small particle of light. Before Einstein it was known that light travels through the straight line, but his prediction was that during the time of travelling the light from a remote star to us it goes bent due to the gravitational force of the sun. In 1915 Einstein said it deflects by $1.74 \mathrm{sec}$. arc. This was proven in the later period (on 29 May, 1919) as a true hypothesis by a group of astronomer headed by Sir Edington. So the classical idea was rejected and thus replaced by Einstein. Einstein first proposed that there is nothing absolute in the world. Space, time, mass, energy, length, motion are relative to the human mind. 'According to the theory, classical mechanics is a special case of a more general mechanics, and is valid only for low velocities i.e, low with respect to the velocity of light in a vacuum .At high velocity, mass is no longer constant, but increases with velocity. Mass is regarded as a form of energy, and is therefore the equivalent of a given amount of energy.' 25

These debates never come to an end because we observe the world from the different perspective which there is thought to be true from both the side. Newton is correct when he is considered within a limited scale. But when we consider him in terms of a greater perspective he becomes obsolete. So where is the reality? Is the universe governed by two different laws? Which one is correct and hence is accepted? Isn't it philosophy that provides the solution?

\section{My own idea about the scientific progress}

My position is neither Popperian nor Fyerebandian, although I think that science means a constant progression on the way to its utmost precision where the absolute truth is yet to be known. We don't actually know whether there is any such truth or not. I don't think like Popper- 'our science is not knowledge'26. On the other hand I don't hold like Feyereband-Anything goes in science $^{27}$. But I do strongly support science and its each activity although it is always limited in terms of its previous scheme. Ninetieth century's physics for example, is limited than twentieth century, similarly the present day's physics is also limited than the upcoming days. This is always on evolvement. Science is based upon the observation and experiment which sometimes appears to be false. But even its falsity is also proven by further experiments and observations. So it does not mean that we shouldn't rely on science. In the history of science we have tried to discover a sequence of better theory. And probably that is the business of the scientists to make better framework of thinking than its previous one. On the way to their journey sometimes it has to reject its previous formula. I have mentioned at the outset that science is always an amendable where it needs correction at its every level.

My view is possibly very close to Hawking where I do believe that if we want to understand the universe at the deepest 
level, we need to know not only how the universe behaves, but why.

$$
\begin{aligned}
& \text { Why is there something rather than nothing? } \\
& \text { Why do we exist? } \\
& \text { Why this particular set of laws and not some other?28 }
\end{aligned}
$$

These questions are philosophical rather than scientific, although Hawkings' view is not positive towards philosophy. But his philosophical question in physics makes immense scope for new knowledge. These above questions can't be solved by physics herself. It needs truly inquisitive enquiry to formulate an acceptable theory. In addition to that, science is based upon inductive formulation where it speaks only of probability. So I do not think that science can go above all confusions from human mind. It is the nature of science that it has got the properties to overcome itself at every level of her position. That is the beauty of science.

\section{References}

1. Russell, Bertrand (1912) : The Problems of Philosophy, A Galaxy Book, New York, Oxford University Press, p.7

2. Chaudhury, Pravas Jivan (1955); The Philosophy of Science, Progressive Publishers, Calcutta, p. 3

3. Ibid., p.3

4. For detail information, See A.C. Benjamin "Science and Philosophy of Science" in Philosophy of Science, Oct.1938, p. 423

5. Chaudhury, Pravas Jivan (1955) : The Philosophy of Science, Progressive Publishers, Calcutta, p.23
6. Russell, Bertrand : History of Western Philosophy Routedge, London and NewYork, p.217

7. Khan, Galib Ashan (1990) : Science, Method and Progress, Bibidha Publishers, p. 3

8. Hawking, Stephen (1988) : A Brief History of Time, Bantham Books, NY, pp-35/36.

9. Ibid-36

10.Hawking, Stephen(1988) : A Brief History of Time, Bantam Books, NY, p.59

11.Chaudhury, Pravas Jivan(1955) : The Philosophy of Science, Progressive Publishers, Calcutta, p.143

12. Planck, $\operatorname{Max}(1933)$ : Where is Science Going? p.202,

13. Hawking, Stephen and Milodinow Leonard : (2010) The Grand Deign BantamPress, London p 87

14. Ibid-103

[Gravity: 'This is the weakest of the four, but it is a longrange force and acts on everything in the universe as an attraction. This means that for large bodies the gravitational force all add up and can dominate over all other forces'2. Electromagnetism; 'This is also long-range and is much stronger than gravity, but it acts only on particles with an electric charge, being repulsive between charges of the same sign and attractive between charges of the opposite sign. This means the electric forces between large bodies cancel each other out, but on the scales of atoms and molecules they dominate. Electromagnetic forces are responsible for all of chemistry and biology'. Weak nuclear force: This causes radioactivity and plays a vital role in the formation of the elements in stars and the early a vital role in the formation 
of the elements in stars and the early universe. We don't, however, come into contact with this force in our everyday lives 'Strong nuclear force' This force holds together the protons and neutrons inside the nuclear of an atom. It also holds together the protons and neutrons themselves, which is necessary because they are made of still tinier particles, the quark... The strong force is the energy source for the sun and nuclear power, but, as with the weak force, we don't have direct contact with it]

15. Grayling, A.C. Scepticism (2004) : (Burr John and Goldinger Milton; Philosophy and Contemporary Issues, Prentice-Hall of India ptv ltd, 2008 p.462)

16. Hawking, Stephen (1995) : Black Holes and Baby Universe and Other Essays. Baulmon Prokason, Calcutta, p.82

17. Doppler effect; The apparent changes in the wavelength of electromagnetic radiation or other wave motion(sound waves) when the source of radiation approaches or recedes from the observer. If the source approaches, the number of waves received per second( frequency) increases, while the number decreases if the source recedes. With regards to light, the special lines shift towards the violet end of the spectrum if the source approaches, and towards the red if the source recedes.

18. Caudwell, Christopher (1939) : The Crisis in Physics, Baulmon Prokashan, Calcuta, p.17

19. Feyerabend, P (1975); Against Method, (London: NLB), p.146

20. Khan, Galib Ashan (2002); Epistemological Negativism and Scientific Knowledge, Jatiya Grantha Prakashan, p.124

21. Law 1. Every body preserves in its state of rest, or of uniform motion in a straight line, unless it is compelled to change that state by forces impressed thereon.
Law 2. The alteration of motion is ever proportional to the motive force impressed; and is made in the direction of the right line in which that force is impressed.

Law 3 . To every action there is always opposed an equal reaction; or the mutual actions of two bodies upon each other are always equal, and directed to contrary parts.

E.A.Burtt (1925) : Metaphysical Foundations of Modern Science, Kegan Paul, p.246

23. Newton: Mathematical Principles of Natural Philosophy, Motte's Translation, 1803, p.311

24. Chaudhury : op.cit., p.29

25. The Penguin Dictionary of Astronomy (ed. Engelbrektson), Penguin Books,p.74

26. Popper, K (1968) : The Logic of Scientific Discovery, New York: Harper and Row, 1968, p.278

27. Feyerabend, P op.cit., pp.27-28

28. Hawking, Stephen and Milodinow Leonard op.cit.,p.171 